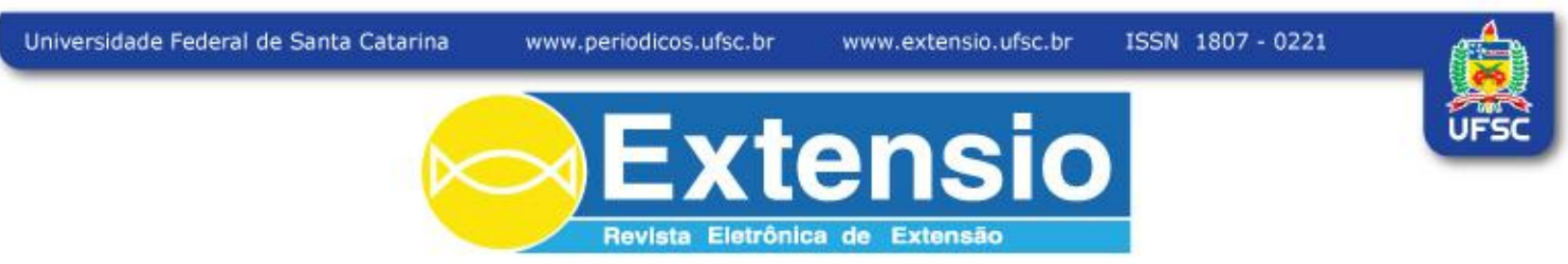

\title{
Pró-bicho Pelotas
}

Área Temática Cultura

\author{
Juliana Corrêa Hermes Angeli ${ }^{1}$ \\ Amanda Carolina Abex Gomes ${ }^{2}$ \\ Andre Martins Ziegler ${ }^{3}$ \\ Andressa Vasconcellos Moreira ${ }^{4}$ \\ Caroline Marmitt Losekann ${ }^{5}$ \\ Greici Maia Behling6 \\ Karina Régia Dias ${ }^{7}$ \\ Júlia Spohr Reinhardt ${ }^{8}$ \\ Lauren Morales Hainzenreder 9 \\ Martha Letícia Machado Dworakowski10
}

\section{RESUMO}

Desenvolvido desde 2012, o Projeto Pró-Bicho Pelotas visa auxiliar protetores voluntários de animais e a ONG SOS Pelotas (organização que atua no resgate e no tratamento de animais abandonados) na obtenção de imagens fotográficas com qualidade dos animais resgatados e que se encontram disponíveis para adoção responsável. Através do e-mail do projeto, são agendadas as sessões fotográficas dos animais. As fotografias são obtidas com equipamento profissional e em um fundo infinito portátil, construído pelos discentes. Dessa forma, a obtenção de imagens pode ser realizada no próprio Centro de Artes ou no local onde os animais se encontram. Após a edição e o tratamento, as imagens são veiculadas em álbuns na página do projeto na rede social Facebook. Juntamente com os álbuns, são divulgados os contatos do protetor que está cuidando dos animais até a adoção. 0 agendamento das sessões, a obtenção de imagens, seu tratamento e sua divulgação são realizados por discentes do Centro de Artes da UFPel que cursaram as disciplinas de Introdução à Fotografia e Fotografia nos cursos de Artes Visuais (Bacharelado e Licenciatura), Design Gráfico e Design Digital. Além de divulgar os álbuns do projeto, na página também são divulgados animais que

\footnotetext{
${ }^{1}$ Docente da área de Fotografia e Produção Cultural do Centro de Artes da Universidade Federal de Pelotas (UFPel). E-mail: julianaangeli@gmail.com.

${ }^{2}$ Acadêmico do curso de Bacharelado em Artes Visuais do Centro de Artes da UFPel.

${ }^{3}$ Acadêmico do curso de Bacharelado em Artes Visuais do Centro de Artes da UFPel.

${ }^{4}$ Licencianda do curso de Artes Visuais do Centro de Artes da UFPel.

${ }^{5}$ Licencianda do curso de Artes Visuais do Centro de Artes da UFPel.

${ }^{6}$ Servidora Técnica Administrativa do Núcleo de Reabilitação da Fauna Silvestre e Centro de Triagem de Animais Silvestres da UFPel (NURFS/CETAS).

${ }^{7}$ Acadêmica do curso de Design Digital do Centro de Artes da UFPel.

${ }^{8}$ Acadêmica do curso de Design Gráfico do Centro de Artes da UFPel e bolsista PROBEC/PREC/UFPel.

${ }^{9}$ Licencianda do curso de Artes Visuais do Centro de Artes da UFPel.

${ }^{10}$ Licencianda do curso de Artes Visuais do Centro de Artes da UFPel e bolsista ROBEC/PREC/UFPel.
} 
estão para adoção e cujo protetor encaminhou as fotografias e solicitações de divulgação de animais desaparecidos ou encontrados. As publicações na página atingem semanalmente cerca de 10 mil usuários. Em 2012, dos 164 animais fotografados, entre cães e gatos, mais de $65 \%$ foi adotado.

PALAVRAS-CHAVES: Adoção de Animais. Fotografia.

\section{PRÓ-BICHO PELOTAS}

A população de animais de rua vem crescendo a cada dia. Não raro, vemos animais errantes, abandonados, com fome, vítimas de doenças e maus-tratos. 0 Brasil possui a segunda maior população de animais domésticos do mundo, chegando a 28 milhões, entre cães, gatos e outros animais (BEHLING, 2011). Apesar de essa estatística incluir animais domésticos e sob a responsabilidade de um tutor, existe nas ruas um crescente número de animais abandonados, ou rejeitados, que vivem nelas expostos a todo tipo de crueldade e indignidade. Conforme a Sociedade Mundial de Proteção Animal (WSPA), existe no mundo 500 milhões de cães, dos quais 75\% vivem nas ruas. A falta de esterilização, tanto dos animais domésticos que possuem tutores quanto dos que estão nas ruas, contribui significativamente para o aumento da população animal. Uma única fêmea canina ou felina e sua prole podem gerar, em dez anos, milhares de novos animais. (BEHLING, 2011)

Embora existam algumas ações pontuais do Poder Público para tentar minimizar os efeitos do descontrole populacional, também existem associações, ONGs ou mesmo protetores voluntários que atuam em prol da diminuição da população de animais de rua. Após o recolhimento, ou resgate devido a maus-tratos, os animais recebem tratamento veterinário, são castrados, vacinados, vermifugados e disponibilizados para adoção responsável. A divulgação para adoção quase sempre é realizada por correio eletrônico (e-mail) ou através das redes sociais e geralmente é acompanhada por fotografias obtidas pelo próprio protetor.

A inspiração para o Projeto Pró-Bicho Pelotas veio através do conhecimento do trabalho da empresa Cão em Quadrinhos de Porto Alegre. Nela são trabalhadas as relações entre a fotografia e os animais de estimação. São retratadas imagens de pessoas e de seus animais de maneira criativa e espontânea. As duas proprietárias da empresa, as irmãs Manoela Trava Dutra e Ana Carolina Trava Dutra, também realizam campanhas 
educativas e auxiliam gratuitamente as protetoras de Porto Alegre obtendo, em seu estúdio, imagens dos animais que estão para adoção, para posterior divulgação.

Muitas vezes, os protetores não dispõem de equipamento adequado para o registro de seus "afilhados"11. Imagens com baixa resolução ou com iluminação pouco apropriada acabam desvalorizando o animalzinho que está para adoção. A fotografia de pets vêm sendo explorada no mercado já há algum tempo. Imagens bem produzidas e tratadas eternizam os momentos vividos pelo cão (ou gato) e seu dono (LIMBERGER, 2011). Porém, nem sempre esses serviços possuem um preço acessível. Para protetores que precisam de imagens de inúmeros animais, esses valores acabam sendo impraticáveis. Notamos que, no caso de animais sem raça definida para adoção, uma imagem com boa qualidade técnica chama a atenção e aumenta consideravelmente as possibilidades de eles conseguirem um novo lar.

Assim, com o objetivo principal de auxiliar na obtenção de imagens fotográficas e auxiliar na divulgação dos animais para adoção de forma gratuita, o projeto de extensão Pró-Bicho Pelotas vem sendo desenvolvido desde março de 2012 na cidade de Pelotas. Foi realizada parceria com a ONG SOS Animais Pelotas, que atua desde 1999 na busca de soluções para o abandono de animais na cidade. Tal ONG realiza ações como o levantamento de fundos para castrações, arrecadação de ração e de remédios para mutirões que são realizados nas comunidades da periferia do município. Além disso, a SOS Animais Pelotas conta com a colaboração de protetores voluntários que resgatam animais abandonados e lhes oferecem tratamento de saúde e alimentação adequada até a adoção. As integrantes da ONG agendam sessões fotográficas de seus "afilhados" através do e-mail ${ }^{12}$ do Projeto Pró-Bicho Pelotas e indicam essa prestação de serviços para protetores independentes da cidade.

Para as sessões fotográficas, foi construído um fundo infinito desmontável com uma estrutura de metal e lona branca. 0 projeto possui, em seu acervo, figurino e acessórios que são utilizados pelos animais durante as fotografias. São utilizadas câmeras profissionais e iluminação natural para a obtenção de imagens. Cada sessão de

\footnotetext{
${ }^{11}$ O termo "afilhado" refere-se ao animal que é "apadrinhado" por um protetor e está recebendo todos os cuidados necessários.

${ }^{12}$ probichopelotas@gmail.com
} 
fotos gera entre 200 e 500 imagens. São selecionadas em média 10 imagens para tratamento, que é realizado com software apropriado. 0 tratamento das imagens objetiva a eliminação de sujeiras ocasionais no fundo infinito ou algum pequeno retoque nos animais. As características dos fotografados não são alteradas. Posteriormente, na página do projeto na rede social Facebook ${ }^{13}$, é criado um álbum com as fotografias escolhidas e tratadas. Na descrição do álbum e de cada imagem, são divulgados o nome do fotografado, sua idade, porte, características de temperamento (brincalhão, agitado, dócil e sua compatibilidade com crianças, cães e gatos) e cuidados já realizados (castração, vacinação e/ou vermifugação). Além disso, são divulgados os contatos do protetor do qual o bichinho está sob a proteção.

Inicialmente, as sessões fotográficas foram previstas para serem realizadas nos finais de semana, a cada 15 dias, nas dependências do Centro de Artes da Universidade Federal de Pelotas. Nossa primeira sessão de fotos foi realizada no final de março de 2012. Foi fotografada uma ninhada de quatro cães com cerca de dois meses de idade, que estavam abrigados em uma casa abandonada próxima à universidade e eram tratados por moradores da região. Após a divulgação, em menos de quatro, dias todos os cães haviam sido adotados.

Quando ocorre a adoção, o protetor responsável informa a equipe do projeto e o álbum é atualizado com a informação "Adotado" e posicionado no final da página dos álbuns. Essa estratégia possibilita que novos visitantes, ao visualizarem a página no Facebook, acessem primeiramente os cães e gatos que se encontram para adoção, aumentando também as possibilidades de conseguirem ser realocados em novos lares.

Além dos álbuns produzidos pelo projeto, a página no Facebook também disponibiliza o serviço de divulgação de animais perdidos ou encontrados, pedidos de auxílio para pagamento do tratamento de resgates feitos pelas protetoras, pedidos de ama de leite para ninhadas encontradas nas ruas, pedidos de casa de passagem e veiculação de animais que estão para adoção e cujas imagens são fornecidas pelas protetoras. São compartilhados também os eventos (Brechó para Arrecadação de Fundos e a Feira de Adoções) e os mutirões realizados pela ONG SOS Animais Pelotas, assim

${ }^{13} \mathrm{https}: / /$ www.facebook.com/ProBichoPelotas 
como atividades de ONGs e associações locais. No ano de 2013, iniciamos uma parceria com a Associação dos Amigos dos Animais Abandonados - ONG A4, da cidade de Capão do Leão, município próximo a Pelotas.

A página do projeto Pró-Bicho Pelotas está sendo seguida por mais de duas mil pessoas, e as publicações atingem em média 10 mil usuários a partir dos compartilhamentos.

Em 2012, foram fotografados 164 animais, dos quais 107 foram adotados, dando um percentual de êxito ao projeto de 65,24\%. Atualmente, devido à grande procura e aos resultados satisfatórios de adoções, as sessões são realizadas semanalmente e não somente nas dependências do Centro de Artes. 0 fundo infinito pode ser transportado até locais que possuem um grande número de animais e também para clínicas veterinárias onde existem animais em condições especiais, ou em tratamento, e que não podem ser deslocados.

Além da lição de cidadania, o projeto também proporciona aos alunos bolsistas e voluntários ${ }^{14}$ aprofundamento dos conhecimentos obtidos nas disciplinas de Fotografia oferecidas nos cursos de graduação do Centro de Artes e qualificação profissional no que se refere à obtenção e tratamento de imagens.

As imagens produzidas apresentam o animal com dignidade. Mostram que não é necessário ser um bichinho com pedigree para ser valorizado. São retratos que trazem cada um deles de maneira única e mostram aos possíveis adotantes que todos animais têm vez. Não é necessário ser um filhote para buscar um lar responsável. Não é necessário ser de raça para ter e dar carinho. Ao serem registrados através dos procedimentos do retrato fotográfico e dos procedimentos de estúdio, lhes são conferidas uma individualidade e uma personalidade. "A fotografia tem o dom de enxergar e demonstrar através das fotos expressões únicas dos pets, transparecendo em cada um deles uma faceta peculiar." (LIMBERGER, 2011, p. 19). As imagens produzidas

\footnotetext{
${ }^{14}$ Além dos acadêmicos voluntários da Universidade Federal, o Projeto Pró-Bicho Pelotas conta com a participação de Camila Petter da Rocha, aluna do curso de Publicidade e Propaganda da Universidade Católica de Pelotas; de Graziele Rosa Gomes, egressa do curso de Bacharelado em Artes Visuais da UFPel; e de Francine Ruas Dias, egressa do curso de Design Gráfico da mesma Instituição.
} 
enfatizam de certa forma que todos merecem uma chance, sejam filhotes, cães ou gatos adultos, com ou sem raça definida.

\section{Referências}

ASSOCIAÇÃO DOS AMIGOS DOS ANIMAIS ABANDONADOS. [Site oficial]. [2013]. Disponível em: <http://www.a4amigos.com>. Acesso em: 13 jun. 2013.

BARTHES, Roland. A câmara clara. Lisboa: Edições 70, 1980.

BEHLING, Greici Maia. Análise da legislação de controle populacional de cães e gatos nos municípios da zona sul do Rio Grande do Sul. 2011. 53 f. Monografia (Especialização). Programa de Pós-Graduação em Direito Ambiental, Universidade Federal de Pelotas, Pelotas, 2011.

BUSSELE, Michael. Tudo sobre fotografia. São Paulo: Círculo do Livro, 1977.

CÃO EM QUADRINHOS. [Site oficial]. [2013]. Disponível em:

<http://www.caoemquadrinhos.com.br>. Acesso em: 20 jun. 2013.

DUBOIS, Philippe. 0 ato fotográfico e outros ensaios. São Paulo: Papirus, 2003.

FABRIS, Annateresa. Identidade visuais: uma leitura do retrato fotográfico. Belo Horizonte: UFMG, 2004.

LIMBERGER, Fernanda Müller. Fotografia de estimação: um estudo de caso que aborda a recordação como desejo de consumo. Porto Alegre, 2011. 92 p. (Projeto de Graduação, Faculdade de Biblioteconomia e Comunicação, Universidade Federal do Rio Grande do Sul).

SOS ANIMAIS PELOTAS. [Site oficial]. [2013] Disponível em:

<http://sosanimaispelotasrs.blogspot.com.br>. Acesso em 15 de junho. 2013.

WSPA. Animais na rua. [2013]. Disponível em: <http://www.wspabrasil.org/trabalhoWSPA/Caesegatos/animaisnarua>. Acesso em: 19 jun. 2013. 